\title{
Promoting Stress Management and Wellbeing for Teachers, A Pilot Study
}

\author{
Stevie-Jae Hepburn ${ }^{1 *}$, Annemaree Carroll ${ }^{1}$ and Louise McCuaig ${ }^{2}$ \\ ${ }^{1}$ School of Education, The University of Queensland, Brisbane, QL, Australia, ${ }^{2}$ School of Human Movement and Nutrition \\ Sciences, The University of Queensland, Brisbane, QL, Australia
}

Objectives: Investigate the change in perceived stress, mindful attention awareness, subjective wellbeing and coping for pre-service teachers (PSTs) and the impact of a pilot 6h Complementary Intervention (Cl).

Method: Phase One $(N=79)$ survey at two timepoints. Perceived Stress Scale, Mindful Attention Awareness Scale, Personal Wellbeing Index and the Brief COPE scale. Phase Two $\mathrm{Cl}$ pre- and post-program self-report measures $(\mathrm{N}=20)$.

Data analysis: Paired-sample and independent sample t-test.

Results: The paired-samples t-test confirmed that perceived stress levels ( $p=0.082)$ for PSTs remain elevated across the duration of the academic year. There was not a significant change for the MAAS and sub-scales of the Brief COPE. There was a significant decrease

OPEN ACCESS

Edited by:

Manpreet Kaur Bagga,

Partap College of Education, India

Reviewed by:

Nathalie Sandra Reid,

University of Regina, Canada

Laura Sara Agrati,

University of Bergamo, Italy

*Correspondence:

Stevie-Jae Hepburn

stevie.hepburn@uqconnect.edu.au

Specialty section:

This article was submitted to

Teacher Education,

a section of the journal

Frontiers in Education

Received: 20 July 2021 Accepted: 12 October 2021

Published: 10 November 2021

Citation:

Hepburn S-J Carroll A and McCuaig L (2021) Promoting Stress Management and Wellbeing for Teachers, $A$

Pilot Study.

Front. Educ. 6:744227.

doi: 10.3389/feduc.2021.744227 in PWI scores ( $p=0.04)$. The participants in the $\mathrm{Cl}$ experienced a significant decrease in perceived stress $(p=0.004)$ pre-program $(M=18.6, S D=7.04)$ and post-program $(M=$ $15.55, S D=6.95)$, effect size $(d=0.48)$. Increase in mindful attention awareness ( $p=$ $0.019)$, pre-program $(M=3.49, S D=0.59)$ and post-program $(M=3.94, S D=0.85)$, effect size $(d=-0.57)$.

Conclusion: The findings suggest that perceived stress for PSTs are at above-average levels and a yoga-based $\mathrm{Cl}$ may provide support for promoting wellbeing and stress management.

Keywords: health, wellbeing, pre-service teachers, stress management, mindfulness, yoga, teacher training

\section{INTRODUCTION}

Teacher stress and wellbeing is an established area for educational research spanning over 40 years (e.g. Jelinek, 1986). Early research highlighted that in some cases, stress could be a motivating factor that encourages behaviour change and improves work ethic among pre-service teachers (PSTs). Conversely, stress has been identified as creating a deleterious effect on PSTs' performance and erode confidence, professional identity and morale. Psychological distress can manifest as physiological ailments or symptoms associated with anxiety, depression, decreased productivity and performance (Wong et al., 2006). Those entering the teaching profession are more likely to have ideological motivation based on empathy and service to others. As reported by the OECD (2020, p. 8) "around $90 \%$ of teachers say that serving a larger social purpose was a major motivation to enter the profession." The contrast between idealistic expectations and the reality of the classroom can be overwhelming and individuals that are "empathetic, sensitive, dedicated, idealistic, and peopleorientated, tend to be the most vulnerable" (Greer and Greer, 1992, p. 169). Often the expectations of 
PSTs do not match the reality of the classroom. How they 'frame' their teaching experience is based on their own experiences as a student, and there can be vast differences between when they were in the classroom as a student and when they return as a teacher (Turner et al., 2012). To cope with professional inadequacy frequently experienced during practicum, PSTs may modify their professional ideals to be less empathic, compassionate and caring and focus on content and student achievement (Lindqvist et al., 2017).

In the general Australian population, psychological and behavioural conditions reported in the Australian National Health Survey are rising. The Australian National Health Survey (Australian Research Council and Universities, 2018) indicated increased psychological and behavioural conditions from 2017 to 18 (20.1\%). Women reported a higher rate than men for high or very high levels of psychological distress in 2017-18 (12.0\%). In 2017-18 the age group with the highest ratings were women aged $18-24$ years (18.5\%) followed by $55-64$ years (16\%) and $25-34$ years (15\%). The highest ratings for men were $45-54$ years (15\%), followed by $18-24$ years $(12.4 \%)$. This information is pertinent to the present study due to the demographic of the teaching profession. The highrisk groups outlined from the Australian National Health Survey align with the demographics of individuals entering the teaching profession. For instance, $76.6 \%$ of registered teachers were female, average 45.6 years in 2020 and $51.7 \%$ aged 45 years and over. The average age of applicants for teacher registration was 35.8 years in 2020 (QCT, 2021). It has been reported that women report higher levels of psychological distress than men in the teaching profession (Deasy et al., 2014). The study was conducted before the COVID-19 pandemic and the Australian Bureau of Statistics reported that 19\% (one in five) Australians reported their mental health was worse or much worse than before the onset of the pandemic in March 2020 (Australian Bureau of Statistics, 2021).

PSTs are reported as experiencing elevated perceived stress scores (Geng et al., 2015; Stallman, 2010). It has been suggested that the elevated level of distress experienced by PSTs is chronic, with slight variance throughout the academic year (Stallman and Hurst, 2016). Conversely, others argue that stress experienced by PSTs can increase throughout their academic studies and reach a peak during placement due to financial concerns resulting from placement workload, family and work commitments and academic assessment (Goddard and O'Brien, 2006; GustemsCarnicer and Calderón, 2013; Le Maistre and Paré, 2010). Grant-Smith et al. (2018) surveyed students from the Faculties of Health and Education at the Queensland University of Technology, Australia $(N=552)$ with education students $(n=$ 172) reporting financial stress, study and work-life balance, interactions with staff/supervising teachers, practicum structure and academic stress as negative aspects of practicum experience. When investigating the experiences of graduate $(n=$ $151)$ and undergraduate $(n=159)$ PSTs, Geng and colleagues (2016) reported that graduate PSTs perceived stress levels were significantly higher than undergraduate PSTs and that the two groups experienced different stressors.

Deasy et al. (2014) indicated that $41.9 \%$ of the 1,557 nursing/ midwifery $(n=473)$ and education students $(n=1,104)$ reported high psychological distress. Positive coping strategies, including seeking social support, were positively correlated to psychological wellbeing. Avoidance behaviours and maladaptive coping strategies identified in the study were linked to adverse health and wellbeing consequences. It was noted that some behaviours that could be seen as helpful for managing stress could result in an increase in distress; for example, alcohol consumption to reduce stress can increase an individual's response to stress. The students were reluctant to utilize professional support services provided at the university. Gustems-Carnicer and Calderón identified that proactive, problem solving coping strategies positively influenced symptoms of phobic anxiety, depression, and psychological distress for PSTs $(N=98)$ whereas avoidance coping strategies were associated with increased psychological distress. The findings indicate a need for health promotion and health education during university education. The argument for providing mindfulness-based training to assist with coping and stress management during university training is presented by Soloway (2016). In particular, the practice of non-judgement is a key element for reducing reactive behaviours and increasing an individual's awareness of the activity within the mind and subsequent habitual behaviours and coping strategies.

Forming positive relationships and interactions within the school community is a significant factor for professional identity, feelings of helplessness and resilience (Lindqvist et al., 2017) during the pre-service and early career period. How a teacher manages the stressors of the profession can be influenced by an individual's sense of wellbeing (Turner et al., 2012) and the transition from PST to early career teacher (ECT) is a critical time (Hemmings and Hockley, 2002) that can significantly influence an individual's career pathway (Murray-Harvey et al., 2000; Le Maistre and Paré, 2010; Le Cornu, 2013). Greater resilience and enjoyment of teaching increase when teachers manage their stress, regulate emotions and experience more positive emotions ( $\mathrm{Gu}$ and Day, 2007). Mindfulness training has been shown to improve teacher-student communication and interactions (Skinner and Beers, 2016) and promote prosocial interaction (Kemeny et al., 2012; Jennings et al., 2013, 2017). Providing PSTs with skills to manage stress may positively influence their career pathway.

Although it has been argued that stress-management programs need to be included in university-level teacher training (Harris, 2011; Hepburn, 2020), there are limited studies investigating the feasibility and benefits of implementing university-level training programs. To date, the research surrounding PSTs includes interventions utilizing a modified Mindfulness-based Stress Reduction (MBSR) program (e.g., Hue and Lau, 2015; Miyahara et al., 2017). Mindfulness-based Interventions (MBIs) specifically designed for younger participants have been adapted for pre-service teachers, for example, the "Learn to Breathe" program (Broderick et al., 2013) (originally targeting adolescents) see Kerr et al. (2017). The present study does not present the argument that a complementary intervention (CI) would create a solution for the complex and multifaceted issue that is PST stress and wellbeing. The issue of teacher stress and the current educational climate and culture in our schools requires a dialectic approach, that is, attention must be directed towards 
stress management strategies and promoting positive wellbeing for teachers. A systems or department level intervention was not feasible in the present study therefore the focus was directed towards secondary (individual) level stress management interventions.

The first aim of the present study was to identify the change in mindful attention awareness, perceived stress and subjective wellbeing for PSTs from the start (Time One, start of Semester One) to the conclusion (Time Two, end of Semester Two) of the academic year (Research Question 2). Based on the literature reviewed it is predicted that the PSTs participating in the study may be experiencing elevated perceived stress levels. Given the argument that there may be a significant link between attention awareness (mindfulness as a state), perceived stress and wellbeing (Hepburn, 2020), the second aim was to investigate the potential for a CI for pre-service teachers to provide personal knowledge and practice strategies for increasing attention awareness and decreasing the stress response (Research Question 2). Based on the literature surrounding MBIs for educators, it is predicted that a CI will result in an increase in MAAS and decrease in PSS.

\section{BACKGROUND}

\subsection{Recommendations for Educators}

It is argued that very little time in teacher education courses is devoted to teaching PSTs the importance of recognizing signs of stress and practical coping strategies they can implement (Gustems-Carnicer and Calderón, 2013). In a study of Primary PSTs $(N=54)$ from an Australian University, Hemmings and Hockley (2002, p. 25) identified that "teachers have not been trained either to handle their stressors or to develop a variety of successful coping mechanisms."

Coping is viewed as a process rather than a trait or outcome (Deasy et al., 2014) and a coping strategy is an adaptive response to a specific stressor (Folkman et al., 1986). An individual's ability to prevent psychological distress is linked to personal resources and coping strategies (Khramtsova et al., 2007). The importance of interpersonal skills for coping with stress was identified by Lindqvist and colleagues (2017). The education students in the study shared that their mentors were important for support yet on the other hand, created additional stress. An important consideration is that individuals' wellbeing can influence how they interact and engage with their peers and colleagues (Le Cornu, 2013).

The importance of programs for PSTs and ECTs that prioritize wellbeing and stress management strategies are consistently cited in research (e.g., Morris and Morris, 1980; Greer and Greer, 1992; Lindqvist et al., 2017). In particular, this research emphasizes the importance of providing information surrounding how stress manifests in the body, and the long-term impact of stress; the importance of nutrition and exercise; muscle relaxation techniques, mentoring, and time management skills. Early research, for example, Greer and Greer (1992) highlighted the need for explicit professional development sessions educating individuals on how stress manifests (physically and psychologically) and provided techniques to counteract stress and tension in the body (relaxation techniques). Furthermore, Greer and Greer stressed the importance of healthy dietary choices and physical exercise must be included. A stress management program or intervention must be holistic in addressing all facets of wellbeing. This approach is supported by the more recent research of Soloway (2016) and the impact of the Mindfulness-Based Wellness Education (MBWE) program. The MBWE from the University of Toronto provides a multifaceted approach to increasing awareness of the importance of wellbeing and stress management through the inclusion of professional development relating to a specific facet of wellbeing; however, the program is primarily a modified Mindfulness-based Stress Reduction (mMBSR) program (Kabat-Zinn, 1991).

The MBSR program developed by Kabat-Zinn (1991) has been extensively trialled in clinical settings, positive psychology (see Ivtzan, 2016) and modified for school settings (e.g. Gold et al., 2010; Flook et al., 2013; Frank et al., 2015). Reported improvements include decreased perceived stress, anxiety, depression and increases in wellbeing and mindfulness. The delivery of the different interventions (e.g. contact time, duration, method of instruction) has varied however, the mindfulness-based techniques and strategies are consistent. There has been extensive growth in mindfulness-based interventions (MBIs) for educators in school settings and the development of a variety of programs. For example, the Cultivating Awareness and Resilience in Education (CARE) program (see Jennings et al., 2013; Sharp and Jennings, 2016; Jennings et al., 2017) and the Stress Management and Relaxation Techniques in education (SMART) program (Roeser et al., 2013). The Community Approach to Learning Mindfully (CALM) program for educators (Harris et al., 2016) moves away from the traditional MBSR program structure (8-weekly sessions, 2-h in length) and includes 16 weekly sessions (20-min in length). The CALM program is also one of the limited studies that include a yoga-based CI.

Carmody and Baer (2008) note that it is worth investigating the benefits of mindful yoga after the unexpected finding from their study of nine different MBSR programs $(n=174)$. The findings indicated that the home yoga practise (versus sitting meditation and body scan) was more strongly associated with increased mindfulness (non-judgement), wellbeing and decreased perceived stress and anxiety, even though the home yoga practise was reported for less total hours than the other formal practices. An interesting point raised by Harris et al. (2016) is that CIs for educators include some yoga postures; however, there are scarce studies that investigate primarily yogabased programs for teacher wellbeing. In fact, in Australia, there are limited yoga-based programs for teachers. However, there have been recent developments in mindfulness-based programs for teachers based on or including the MBSR program (e.g., Hwang et al., 2019).

In the present study, the CI promoted integrated wellbeing and included strategies for stress management drawn from the system of Yoga. The aim was to highlight the need for stress management and health and wellbeing promotion through professional learning and practical experience. Teachers who receive 
TABLE 1 | Steps/Limbs in the system of yoga.

\begin{tabular}{llll}
\hline & Limb/Step & \multicolumn{1}{c}{ Focus } & \multicolumn{1}{c}{ Description } \\
\hline 1 & Yama & $\begin{array}{l}\text { External focus } \\
\text { Internal focus }\end{array}$ & Ethical approach \\
2 & Niyama & Steady posture & Postures \\
\hline 3 & Asana & Expansion of energy & Breathing techniques \\
\hline 4 & Pranayama & Sensory withdrawal & Meditation practices \\
\hline 5 & Pratyahara & Concentration & \\
6 & Dharana & Meditation & \\
7 & Dhyana & Self-realization & \\
8 & Samadhi & &
\end{tabular}

training in health promotion (at university) are more likely to engage in health promotion activities once employed as a registered teacher (Speller et al., 2010). This supports the argument for health promotion and wellbeing initiatives at the pre-service level.

\subsection{The System of Yoga and Dimensions of Wellbeing}

Given the extensive history of the practice of yoga, there is no one single definition. Patanjali defines yoga as "the controlling or stilling" (Pradhan, 2014). Modern interpretations of yoga are drawn from Patanjali's Sutras and the teachings from the Bhagavad Gita (circa 600-100BCE). The Yoga Sutras are grouped into "eight limbs" in the system of Yoga. Limbs one through five are preparatory steps for limbs six through eight (see Table 1). The Ethical Principles (limb one and two) yamas and niyamas are not based on moral or value judgements or religious connection; the aim is to regulate emotions, promote positive social behaviours and quiet the mind (Cope, 2006), therefore promoting emotion regulation. Asana were traditionally used to prepare the body for meditation and extended periods of sitting or lying in meditation (Feuerstein, 2011). The modern Western perception of yoga emphasizes the importance of the physical practice (asana) and basic relaxation techniques (meditation), however asana is not merely a form of exercise but a set of preparatory steps for the practitioner (Pradhan, 2014). The fourth limb pranayama (breathing techniques) assists the practitioner in calming the body and mind, increasing mind-body awareness (Gard et al., 2014). Since respiration is essential for survival, changes in respiration are given the highest priority (Streeter et al., 2012) and there is a bidirectional relationship between breathing and emotion (Brown and Gerbarg, 2005b). Philippot et al. (2002) suggested that emotions can be induced by using specific instruction and altering breathing patterns. It was reported that feelings of joy are associated with "regular, moderately deep and slow breathing through the nose with minimal thoracic tension, tremors, and sighs" (p. 615). This breathing pattern aligns with some of the controlled breathing techniques (pranayama) included in yoga practice. In Table 1, limbs five to eight are grouped as 'meditation practices'. An integrated yoga practice, includes the ethical princples within the guided meditation practices. Often the terms yoga, meditation and mindfulness are used interchangeably. The system of yoga includes mindfulness practices (e.g., focused attention [FA] and open monitoring $[\mathrm{OM}]$ meditation) which are included in the present study intervention. In fact, research surrounding body awareness and mindfulness have indicated that the same mechanisms may operate in yoga and mindfulness-based interventions (Gard et al., 2012).

Mind-body therapies are not easily classified as either topdown or bottom-up mechanisms. Yoga and progressive muscle relaxation ('body scan meditation') include both bottom-up and top-down mechanisms, for example, peripheral sensory vessels stimulated by visceral activities (e.g., decreased muscle tension) and top-down mechanisms of focused attention and conscious relaxation (Taylor et al., 2010). Importantly, initiating bidirectional mechanisms creates reciprocal feedback and evidence suggests "mind-body practices incorporate numerous therapeutic effects on stress responses, including reductions in anxiety, depression, and anger, and increased pain tolerance, selfesteem, energy levels, ability to relax, and ability to cope with stressful situations" (Kim et al., 2013, p. 827).

An intervention for educators that includes an integrative practice of yoga has the potential to provide a holistic approach for promoting wellbeing. The six-factory model of psychological wellbeing (Ryff and Singer, 1996; 2006) was adopted in the present study. The six-factor model includes the following dimensions:

- Self-acceptance: attitude towards oneself

- Autonomy: self-determination and independence

- Personal growth: self-realization

- Positive interpersonal relationships: empathy and affection

- Sense of purpose in life: goals, intention, and direction

- Environmental mastery

The qualitative findings were linked to the dimensions of wellbeing however, due to the large volume of data collected in the study, the qualitative findings are not reported in this paper.

\section{METHODS}

\subsection{Procedure}

The study was included in a Higher Degree by Research (Doctoral of Philosophy) and complied with the provisions contained in the National Statement on Ethical Conduct in Human Research (2007) (Australian Research Council and Universities, 2018) and the regulations governing experimentation on humans. The protocol was approved by The University of Queensland Human Research Ethics Committee (approval number 2017002108) and the five universities included in the study.

\subsubsection{Phase One}

The survey instruments were prepared and formatted in Qualtrics (2005). The participant information letter and consent form were included in the survey, and a link produced for distribution. The participants were recruited via student email accounts at the start of Semester one, February-March (Time One). The student 


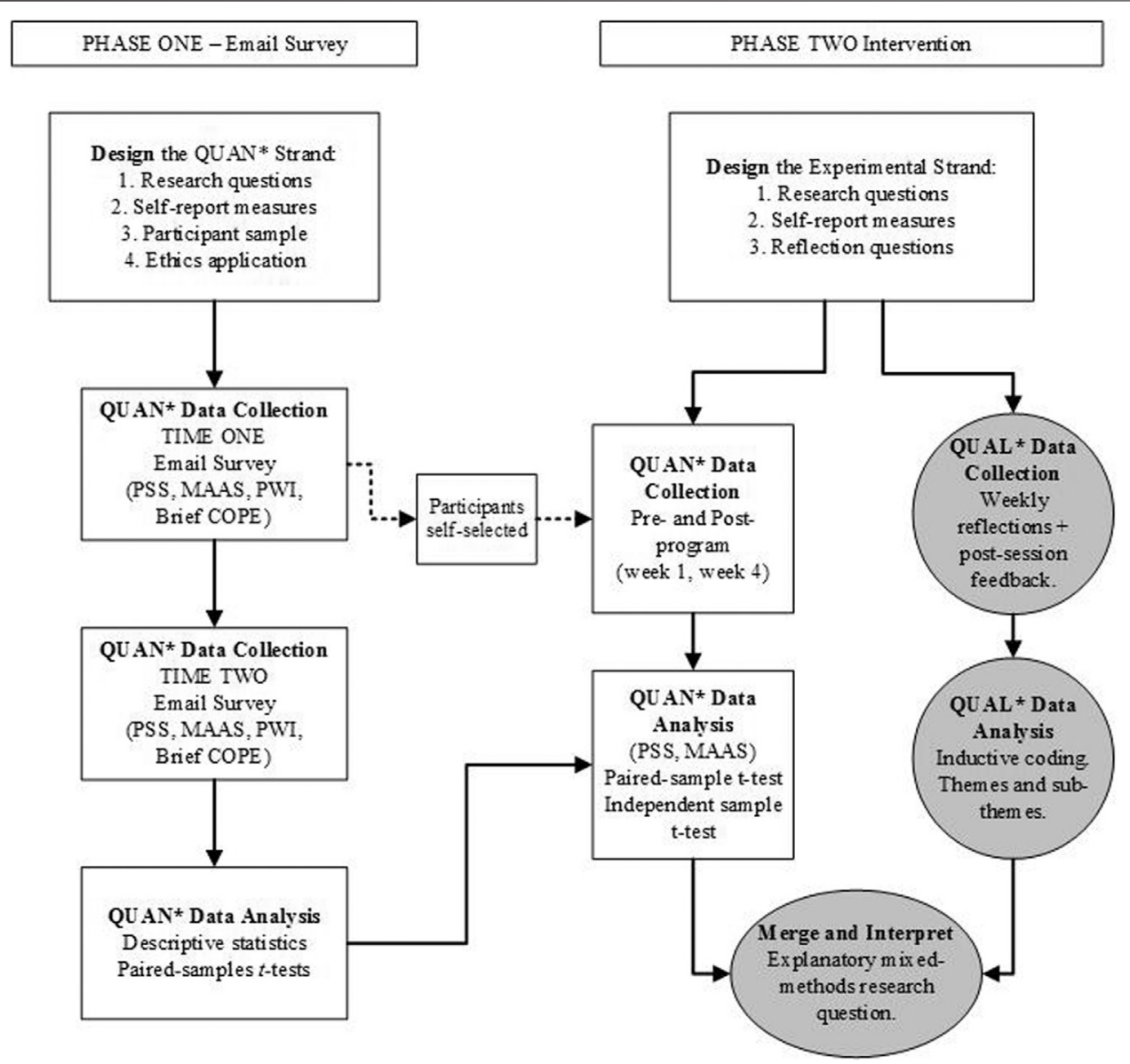

FIGURE 1 | Study design flow diagram, Phase One and Phase Two; QUAL*, qualitative, QUAN*, quantitative.

services department at each university compiled a list of students enrolled in full-time initial teacher training degrees (ITT) (e.g. undergraduate Bachelor of Education/dual-degree, post-graduate Master's of Education). The survey link was distributed via email, newsletter and course coodinators at five Queensland Universities. The survey consisted of 80 questions in total and took approximately $15 \mathrm{~min}$ to complete. The participants were asked to provide a valid email address to receive the following survey link (Time Two). Students that were not enrolled in ITT programs were excluded from the study. The primary outcome of Phase One is measured by the levels of perceived stress and subjective wellbeing reported by PSTs. The secondary outcome is measured by the coping strategies identified and the level of attention awareness reported by PSTs. An additional secondary outcome was the opportunity to identify the perceived stress levels experience by students at three stages in ITT, for example, "first-year", "mid-degree," and "final-year" students.

\subsubsection{Phase Two}

The participants were recruited via the email survey (Phase One) and promotional material (advertising and screening strategies; Lee 1993) via school and university social media networks. The students did not have to complete the survey (Phase One) to be included in the intervention group (Phase Two). The participants from Phase One indicated their interest in the Integrated Wellbeing and Stress Management program at the end of the survey. After registering for the event via Eventbrite (events management online platform) the program details and participation requirements (detailed in the participant information letter) were sent via email. The participants completed the baseline survey 1 week prior to the first session. Multiple datasets were collected throughout the intervention period (e.g. parallel data collection of quantitative and qualitative data (Creswell and Plano Clark, 2018). After the intervention period had concluded, the data was analyzed separately followed by subsequent merging of the data (Creswell and Plano Clark, 2018). The qualitative datasets (shaded grey in Figure 1) are reported elsewhere (see Hepburn, 2020). The survey study (Phase One) was included in another study investigating the link between mindful attention awareness, perceived stress and subjective wellbeing (findings reported elsewhere, see Hepburn, 2020).

The participant sample from the email survey (Phase One) were compared to the baseline data from the intervention group and the datasets were statistically similar therefore the Phase One sample could serve as a control group. The 


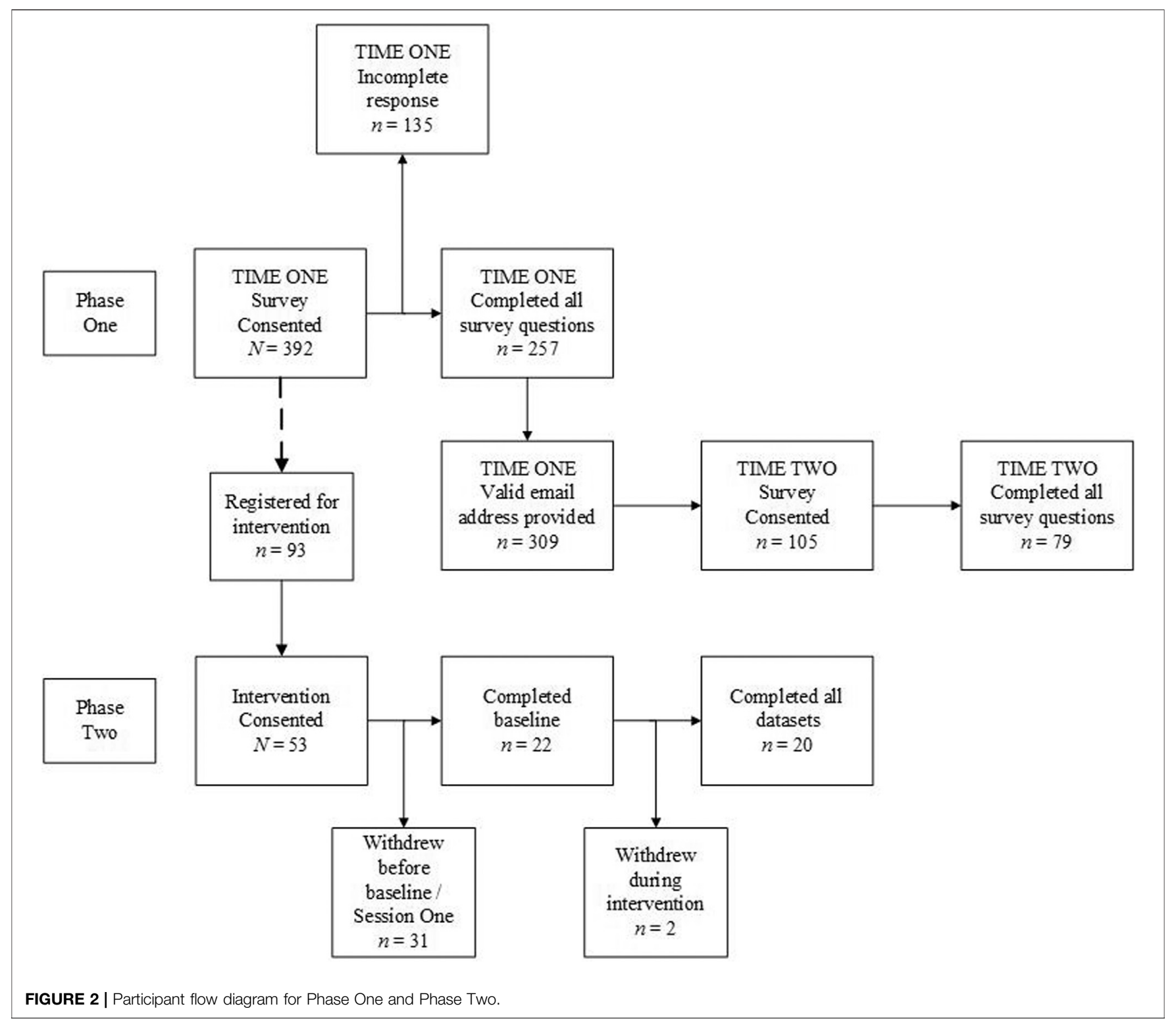

primary outcome of the intervention was to identify the level of perceived stress and mindful attention awareness (measured by the PSS and MAAS) reported by the participants. Secondary outcomes related to the participant's experiences were reported in the qualitative datasets (e.g. participant reflections, reported elsewhere, Hepburn, 2020).

\subsection{Participants}

\subsubsection{Phase One}

At Time One, 392 participants consented to complete the online survey and 257 valid responses were recorded; incomplete responses were excluded. The participants that provided a valid email address $(N=309)$ were sent the survey via email at the end of the second semester with the same instruments for Time One and Time Two. The participant responses from Time
One and Time Two were match using participant codes and incomplete responses were removed (Time Two, valid response included $N=79$ ). The participant numbers for the study are illustrated in the participant flow diagram (Figure 2). The participant sample characteristics are summarised in Table 2. The characteristics of the participant sample at Time Two mirrored the sample from Time One, for example, $60.5 \%$ of the 79 participants were aged between 20 and 24 years. At Time One the students had commenced the first semester of the academic year (e.g. March) and Time Two was at the end of Semester Two (e.g. November). The timing of the survey distribution may provide context for the decreased survey completion, for example, Time Two may have been during the assessment period. The survey link was distributed to students from five different universities; therefore the assessment requirements may have varied across the participant sample. 
TABLE 2 | Study two participant characteristics.

\begin{tabular}{lcccc}
\hline & $\begin{array}{c}\text { Control } \\
(\mathbf{N = 7 9 )}\end{array}$ & \multicolumn{2}{c}{$\begin{array}{c}\text { Intervention } \\
\text { group } \\
\text { (N= 20) }\end{array}$} \\
\cline { 2 - 5 } Characteristic & \% & N & \% & N \\
\hline Female & 88 & 67 & 95 & 19 \\
Male & 11 & 9 & 5 & 1 \\
Fulltime study & 84.8 & 67 & 90 & 18 \\
Part-time study & 15.2 & 12 & 10 & 2 \\
Single Undergraduate degree & 54.4 & 43 & 70 & 14 \\
Dual Undergraduate degree & 26.6 & 21 & 15 & 3 \\
Postgraduate degree & 15 & 19 & 15 & 3 \\
First-year of study & 24 & 19 & 30 & 6 \\
Mid-degree (second or third year) & 48 & 38 & 55 & 11 \\
Final-year of study & 27 & 22 & 25 & 5 \\
Lower Primary (Prep-Grade 2) & & & 40 & 8 \\
Upper Primary (Grade 3-6) & & & 35 & 7 \\
Secondary (Grade 7-9) & & & 20 & 4 \\
Secondary (Grade 10-12) & & & 5 & 1 \\
\hline
\end{tabular}

\subsubsection{Phase Two}

The PSTs that registered for the intervention (Integrated Wellbeing and Stress Management program) $(N=93)$ were from four universities within Queensland, Australia. Students that were not enrolled in ITT programs were excluded from the study. No prior experience with yoga or meditation was required. The participant flow diagram (Figure 2) indicates the number of participants at each stage of the intervention. Of the final participant group $(N=$ 20), 40\% were aged between 19 and 24 years, 30\% were aged between 25 and 29 years, and the remaining $30 \%$ were 30-44 years. The participants in Phase One were not required to indicate the grades they had taught on practicum therefore this information is not included in Table 2. Due to the participant sample including students from different universities and ITT degrees, it was impossible to identify a time when the students were not attending university classes. Therefore, the intervention was held mid-year (June-July) to avoid the practicum period at the end of Semester Two for most ITT degrees. The baseline questions included a combination question (Creswell, 2014) regarding previous experience with yoga or meditation to provide relevant background information. For example, have you had any previous experience with yoga/meditation (yes/no)? If yes, please provide a brief description of your experience. Twenty-five percent had never attempted yoga or meditation practices whereas $60 \%$ of the participants had previously attended a yoga class or introductory workshop or specialist class (e.g., prenatal yoga).

\subsection{Measures}

Mindful Attention Awareness Scale (MAAS). The MAAS was included to measure the change in attention awareness (Brown and Ryan, 2003). The MAAS has been previous included in studies examining MBIs for educators (e.g. Kostanski, 2007; Kemeny et al., 2012; Hue and Lau, 2015; Brown, 2017). The 15-item self-report measure does not produce sub-scales (facets), it is scored to produce an overall score for attention awareness (mindfulness) as a state not a trait. Commonly used scales in MBIs focus on the facets of mindfulness (e.g. Five Facets of Mindfulness
Questionnaire Baer et al., 2006). The MAAS is a 6-point Likert scale focuses on dispositional mindfulness and uses indirect items. E.g. I rush through activities without being really attentive to them. Indirect items are preferred for examining the characteristic of mindfulness as a natural state, that is, when an individual enters into a mindful state. The MAAS has reported high test-retest reliability, convergent validity, known-group validity, and internal consistency levels from 0.80 to 0.90 (Brown and Ryan, 2003).

Perceived Stress Scale (PSS). The PSS (Cohen et al., 1983) is an established 10 item self-report measure used to assess psychological distress. The PSS has been included in studies examining the use of MBIs for teacher wellbeing (Katz et al., 2016; Hester, 2017), evaluating PST stress levels (Geng et al., 2015; 2016; Hopkins et al., 1997) and PST wellbeing (Hue and Lau, 2015; Brown, 2017; Kerr et al., 2017). The PSS has been included as an evaluative measure in studies including MBIs from the health sciences (Carlson et al., 2004; Poulin et al., 2008; Chambers et al., 2016). The PSS uses a 5-point Likert scale. Summed scores above 20 are reported as "high stress" scores and 13 is considered an "average stress" score. In a US population study $(N=2,387)$, the reported norm group scores were 13.7 for females $(n=1,406)$ and 12.1 for males $(n=926)$ (Cohen, 1994). The reported coefficient alphas ranged from 0.77 to 0.78 (Jennings et al., 2017).

Personal Wellbeing Index (PWI). The International Wellbeing Group developed the PWI from the Comprehensive Quality of Life Scale (ComQOL) (Cummins, McCabe, Romeo, and Gullone, 1994). The PWI was included to provide an overall score for subjective wellbeing and at present, the PWI has not been included in previous MBIs for educators. The seven domains from the ComQOL have been validated as accurate measurements for subjective wellbeing and life satisfaction (Cummins, 1996). The 11-point End-Defined Response scale includes the domains of: health, safety, future security, achievement in life, standard of living, relationships, spirituality and standard of living. The Cronbach alpha range is 0.70 and 0.85 in Australian and international studies (International Wellbeing Group, 2013).

Brief COPE Scale. The Brief COPE Scale (Carver et al., 1993) was included to measure coping strategies, and has previously been used to assess stressors for tertiary students (Sam, Muttusamy, Yee, Ayapanaido, and Parasuraman, 2016). The Brief COPE Scale was developed from the 60-item full COPE Inventory (Carver, Scheier, and Kumari Weintraub, 1989). The dispositional format was used for the 28-items; for example, I try to get advice or help from other people about what to do. The 4point Likert scale items are grouped into 14 sub-scales. The subscales were ranked in order of most frequently adopted coping styles for the participant sample. All 14 sub-scales have a coefficient alpha above 0.60 (Carver, 1997). All of the subscales were included in the results however, the sub-scales of consideration in the present study are active coping, planning, positive reframing, and acceptance due to the connection with mindful attention awareness (mindfulness) (Skinner and Beers, 2016).

\subsection{Data Preparation and Analysis}

Responses to the self-report measures were exported from Qualtrics (2005) (online survey software) to IBM SPSS 
Statistics (Version 26), cleaned and re-coded as necessary. Descriptive and inferential statistics were completed for all datasets, and the data met the required assumptions for paired-sample $t$-tests. The participant dataset from Phase One was coded as "first year," "mid-degree," and "final year" to identify their stage in ITT. A Shapiro-Wilk test confirmed normality of the datasets for Phase Two and a paired-sample $t$-test was completed for the MAAS and PSS for the intervention group $(N=20)$. An independent samples $t$-test was completed to compare the control (Phase One, Time One) and Phase Two intervention group (baseline) MAAS and PSS scores and the control (Phase One, Time Two) and Phase Two post-intervention scores.

\subsection{Intervention - Integrated Wellbeing and Stress Management Program}

The intervention was developed after the review of the recommendations from the literature and the mechanisms for supporting stress management. The mechanisms for stress management included in the intervention and the intervention design are detailed elsewhere (see Hepburn et al., 2021). Professional learning that is relevant for PST is recommended for supporting teacher resilience (e.g., Mansfield et al., 2016). MBIs for educators include yoga postures to increase mindfulness (Harris et al., 2016), whereas a unique aspect of the Integrated Wellbeing and Stress Management program is that the postures and techniques were specifically selected to align with the focus for each unit and provide strategies (resources) for the participants. Previous MBIs and CIs for educators focus on the application of mindfulnessbased techniques and strategies in professional settings only (e.g., Roeser et al., 2013; Jennings et al., 2017) whereas the present program focused on professional and personal practical applications and information surrounding the benefits. The 6-h program was delivered as three weekly sessions that were 2 -h in length:

- 45-60-min of theory to support the activities for the session

- 15-30-min of reflection and group discussion activities

- 20-30-min of movement/posture practise

- Home practise determined by the participants

\subsubsection{Theoretical Component}

Unit 1: Psychological Wellbeing:

- The stress response and chronic stress.

- Habitual stress reactions and the signs of stress (physiological and psychological).

- Yoga, Mindfulness and Meditation

Unit 2: Physiological Wellbeing:

- Holding stress or tension in the body: layers of tension.

- The impact of stress on the digestive system.

- The gut, mental and physical health.

Unit 3: Social (interpersonal) Wellbeing:
- Compassion and self-compassion.

- Gratitude and self-gratitude.

- Reducing isolation and supporting wellbeing.

The underlying concepts from the system of yoga were embedded throughout the program. The participants were not taught about yogic philosophy, moreover, the integrated (holistic) approach from the system of yoga, influenced the program design. For example, identification of the stress response and habitual behaviours, aligns with the notion of ethical principles (introspection, Niyama-internal focus, self-awareness, habits). Similarly, considering compassion for the self and others aligns with ethical principles of behaviour towards others (Yama-external focus). Physiological wellbeing (e.g. gut health) relates to the ethical principle of caring for the body (Niyama).

\subsubsection{Practical Component}

The practical component increased in duration each session. Each session included breathing techniques (pranayama), physical postures (asana), and guided meditation (e.g. Yoga Nidra).

In general, yoga postures and the many variations aim to increase range of motion, endurance, flexibility, balance, strength, and activate internal muscle groups. Strengthening muscles can reduce the impact of conditions such as sarcopenia (loss of muscle tone), arthritis and back pain, and overall improved balance in the body reduces muscular imbalance and patterning, which decreases the risk of injury (McCall, 2007). Postures can be hypertonic (strength and muscle tension) and hypotonic (relaxation in supine positions). The movement into and out of postures is synchronized with the breath. Researchers have investigated the effect of postures (forward or backbends and standing postures) on mood states with positive and energy-mood states increasing and negative mood states decreasing after Yoga Therapy Iyengar yoga practice (Shapiro and Cline, 2004). The yoga poses included in the program were specifically selected to target the stress response and decrease muscle tension.

Breathing exercises can be completed as stand-alone practises or in conjunction with specific poses and sequences, depending on the style of yoga. Focused Attention (FA) meditation often involves the breath as the object of awareness. This is most commonly practised as diaphragmatic (abdominal) breathing, where the practitioner visualizes the breath filling from the lower abdomen to the throat in a rhythmic manner (Schmalzl et al., 2016). FA and Open Monitoring (OM) meditation practices were embedded throughout the program, including various objects of attention for the FA practices, for example, the breath or a positive experience. OM meditation was included in the guided meditation practice.

Guided meditation techniques were included in both the theoretical (e.g., reflection activities) and practical components of each session. The meditation practices included in an integrated yoga practice are present throughout the different aspects (e.g., physical postures, breathing awareness, reactivity, and body sensations). Yoga 
TABLE 3 | Summary of Chonbach's Alpha levels for Phase One and Two.

\begin{tabular}{|c|c|c|c|c|}
\hline \multirow[t]{3}{*}{ Scale } & \multicolumn{2}{|c|}{ Phase one } & \multicolumn{2}{|c|}{ Phase two } \\
\hline & \multicolumn{2}{|c|}{ Cronbach's alpha $\alpha$} & \multicolumn{2}{|c|}{ Cronbach's alpha a } \\
\hline & Time one & Time two & Pre-program & Post-program \\
\hline Mindful Attention Awareness & 0.88 & 0.88 & 0.76 & 0.92 \\
\hline Perceived Stress & 0.88 & 0.87 & 0.90 & 0.90 \\
\hline Personal Wellbeing Index & 0.86 & 0.86 & & \\
\hline Brief COPE Scale & 0.88 & 0.67 & & \\
\hline
\end{tabular}

TABLE 4 | Paired Sample t-test PSS, MAAS, PWI Results Summary ${ }^{2}$.

\begin{tabular}{|c|c|c|c|c|c|c|c|c|c|c|}
\hline & \multirow[b]{2}{*}{$N$} & \multicolumn{2}{|c|}{ Time one } & \multicolumn{2}{|c|}{ Time two } & \multicolumn{5}{|c|}{ Paired-sample $t$-test } \\
\hline & & Mean & SD & Mean & SD & $\overline{\mathbf{x}}_{\boldsymbol{d}}$ & $s_{d}$ & $\hat{\mathbf{d}}$ & $t$ & $p$-value \\
\hline PSS & 74 & 21.19 & 6.175 & 19.84 & 5.866 & 1.35 & 6.58 & 0.2 & 1.764 & 0.082 \\
\hline MAAS & 72 & 3.49 & 0.72 & 3.48 & 0.81 & 0.007 & 0.64 & 0.01 & 0.098 & 0.922 \\
\hline PWI & 79 & 57.43 & 10.08 & 55.24 & 11.12 & 2.1 & 9.5 & 0.23 & 2.04 & $0.04^{a}$ \\
\hline
\end{tabular}

aIncluding mean, standard deviation Time One and Two; mean of the difference ( $\bar{x} d)$, standard deviation of the sample of differences (sd), $t$-value and p-value.

Nidra is a form of guided meditation that has been utilized in some education settings. For example, school counsellors (Birdsall et al., 2011) and university students (EastmanMueller et al., 2013). In the present program the Yoga Nidra meditation practise was adjusted to suit the focus for each session, for example, the intention for the Physiological Wellbeing unit focused on tension in the body and allowing the body to rest. Similarly, the FA meditation was adjusted to suit the focus for each session, for example, focusing on areas of tension or relaxation in the body.

\section{RESULTS}

There was a high level of internal consistency (Cronbach's alpha above 0.70 ) at Time One for the MAAS, PSS, PWI in Phase One and Phase Two. The internal consistency for the Brief COPE Scale was consistent with reported levels (e.g. $\alpha=0.60$; Carver, 1997) (Table 3).

\subsection{Phase One}

A paired-samples $t$-test analysis was completed to address Research Question 1:

1. Is there a change in perceived stress, mindful attention awareness, subjective wellbeing and coping for pre-service teachers from the start to the conclusion of the academic year.

The paired-samples $t$-test results for the PSS, MAAS and PWI are presented in Table 4. The reported norm population score for the PSS is 14.2 for individuals 18-29 years (Cohen, 1994). Scores above 20 are regarded as "high stress" (Cohen et al., 1983). The difference in the mean scores for PSS $(n=74)$ at Time One $(\mathrm{M}=$ $21.19, \mathrm{SD}=6.175)$ and PSS at Time Two $(\mathrm{M}=19.84, \mathrm{SD}=5.866)$ for the conditions $t(73)=1.764, p=0.082)$ do not support the contention that the perceived stress levels change (increase or decrease) from the start to the conclusion of the academic year. At Time One and Two, 50\% of the participants reported a score above 20 ("high stress").

The mean PSS scores were determined for each sub-group: "first year," "mid-degree," and "final year" for Time One and Time Two. All the sub-groups are above the reported norm population score (12.3-13.7) (Cohen, 1994) suggesting elevated stress levels across all ITT degrees. The paired samples $t$-test $\left(\bar{x}_{d}=\right.$ $\left.1.35, s_{d}=6.58\right)$ indicated a small effect size $(d=0.2)$ (Evans, 1996) from Time One to Time Two (summarized in Table 5). The MAAS scores and PWI scores for each sub-group are included in Tables 6, 7, respectively.

The MAAS $(n=72)$ at Time One $(\mathrm{M}=3.49, \mathrm{SD}=0.72)$ and Time Two $(\mathrm{M}=3.48, \mathrm{SD}=0.81), t(71)=0.098, p=0.922)$ did not produce a significant change. The paired samples $t$-test $\left(\bar{x}_{d}=\right.$ $\left.0.007, s_{d}=0.64\right)$ indicated a small effect size $(d=0.01)$ (Evans, 1996). The results were below the normative mean range for adults and college-aged students (4.2 and 3.83 respectively) (Brown and Ryan, 2003).

For the PWI scores, the $p$-value was less than 0.05 therefore there was a significant change (decrease) in the mean scores for subjective wellbeing $(n=79)$ at Time One $(\mathrm{M}=57.43, \mathrm{SD}=$ $10.08)$ and Time Two $(\mathrm{M}=55.24, \mathrm{SD}=11.12)$ conditions; $t(78)=$ 2.04, $p=0.04)$. The paired samples $t$-test $\left(\bar{x}_{d}=2.1, s_{d}=9.5\right)$ indicated a small effect size $(d=0.23)$ (Evans). The PWI scores were below the reported norm for Western countries (70-80 points) (International Wellbeing Group, 2013).

The Brief COPE Scale included 14 sub-scales, at Time One and Two, acceptance and self-blame were the highest reported coping strategies with religion and substance use the lowest. Paired-samples $t$-tests for the sub-scales for the Brief COPE Scale (see Table 8) did not produce significant results for Time One and Time Two. The narrow confidence intervals suggest the sample size and variability of the sample are 
TABLE 5 | PSS Score Summary Time One and Time Two.

\begin{tabular}{|c|c|c|c|c|c|c|c|c|c|c|}
\hline & \multicolumn{5}{|c|}{ Time one } & \multicolumn{5}{|c|}{ Time two } \\
\hline & $\mathbf{N}$ & Min & Max & Mean & SD & $\mathbf{N}$ & Min & Max & Mean & SD \\
\hline First year & 19 & 10 & 37 & 20.59 & 7.15 & 19 & 9 & 33 & 20.47 & 6.63 \\
\hline Mid-degree & 38 & 8 & 33 & 20.19 & 5.92 & 38 & 6 & 30 & 18.68 & 5.75 \\
\hline Final year & 22 & 15 & 32 & 23.55 & 5.35 & 22 & 11 & 31 & 21.73 & 5.11 \\
\hline
\end{tabular}

TABLE 6 | MAAS scores Summary Time One and Time Two.

\begin{tabular}{|c|c|c|c|c|c|c|c|c|c|c|}
\hline & \multicolumn{5}{|c|}{ Time one } & \multicolumn{5}{|c|}{ Time two } \\
\hline & $\mathbf{N}$ & Min & Max & Mean & SD & $\mathbf{N}$ & Min & Max & Mean & SD \\
\hline First year & 18 & 2.67 & 4.73 & 3.71 & 0.73 & 19 & 2.33 & 4.87 & 3.64 & 0.63 \\
\hline Mid-degree & 38 & 2.00 & 4.67 & 3.45 & 0.69 & 35 & 1.93 & 5.00 & 3.57 & 0.74 \\
\hline Final year & 20 & 2.20 & 5.00 & 3.38 & 0.68 & 21 & 1.47 & 5.20 & 3.21 & 0.97 \\
\hline
\end{tabular}

TABLE 7 | PWI scores summary Time One and Time Two.

\begin{tabular}{|c|c|c|c|c|c|c|c|c|c|c|}
\hline & \multicolumn{5}{|c|}{ Time one } & \multicolumn{5}{|c|}{ Time two } \\
\hline & $N$ & Min & Max & Mean & SD & $N$ & Min & $\operatorname{Max}$ & Mean & SD \\
\hline First year & 19 & 51 & 83 & 64.95 & 8.61 & 19 & 40 & 78 & 60.37 & 12.55 \\
\hline Mid-degree & 38 & 23 & 82 & 61.53 & 12.39 & 38 & 8 & 82 & 61.11 & 13.57 \\
\hline Final year & 21 & 44 & 90 & 62.95 & 11.01 & 22 & 47 & 89 & 65.55 & 10.60 \\
\hline
\end{tabular}

TABLE 8 | Brief COPE Scale Paired Sample t-test Results Summary ${ }^{2}$.

\begin{tabular}{|c|c|c|c|c|c|c|c|c|c|}
\hline \multirow[t]{2}{*}{ Brief COPE sub-scale } & \multicolumn{2}{|c|}{ Time one } & \multicolumn{2}{|c|}{ Time two } & \multicolumn{5}{|c|}{ Paired-sample $t$-test } \\
\hline & Mean & SD & Mean & SD & $\overline{\mathbf{x}}_{\boldsymbol{d}}$ & $s_{d}$ & $\hat{\mathbf{d}}$ & $t$ & $p$-value \\
\hline Acceptance & 5.97 & 1.435 & 6.20 & 1.324 & -0.129 & 1.296 & -0.1 & -0.830 & 0.409 \\
\hline Self-blame & 6.06 & 1.587 & 5.99 & 1.548 & 0.129 & 1.493 & 0.08 & 0.720 & 0.474 \\
\hline Planning & 5.82 & 1.509 & 5.92 & 1.506 & 0.087 & 1.292 & 0.06 & 0.559 & 0.578 \\
\hline Self-distraction & 5.69 & 1.468 & 5.84 & 1.672 & -0.300 & 1.645 & -0.2 & -1.526 & 0.132 \\
\hline Instrumental support & 5.35 & 1.678 & 5.50 & 1.754 & -0.088 & 1.637 & -0.05 & -0.445 & 0.658 \\
\hline Humour & 5.32 & 1.826 & 5.22 & 1.882 & -0.071 & 1.478 & -0.04 & -0.404 & 0.687 \\
\hline Positive reframing & 5.13 & 1.659 & 5.18 & 1.565 & -0.217 & 1.561 & -0.1 & -1.157 & 0.251 \\
\hline Venting & 4.93 & 1.334 & 5.01 & 1.164 & -0.214 & 1.166 & -0.2 & -1.538 & 0.129 \\
\hline Active coping & 5.01 & 0.874 & 5.00 & 0.972 & -0.103 & 1.135 & -0.1 & -0.748 & 0.457 \\
\hline Behavioural disengagement & 4.36 & 1.198 & 4.58 & 1.239 & -0.200 & 1.187 & -0.1 & -1.410 & 0.163 \\
\hline Emotional support & 4.21 & 1.097 & 4.18 & 1.243 & -0.057 & 1.178 & -0.04 & -0.406 & 0.686 \\
\hline Denial & 4.13 & 0.949 & 4.07 & 0.896 & -0.143 & 1.067 & -0.1 & -1.120 & 0.267 \\
\hline Religion & 3.80 & 2.031 & 3.77 & 2.078 & 0.143 & 1.171 & 0.1 & 1.021 & 0.311 \\
\hline Substance use & 2.73 & 1.120 & 2.66 & 0.864 & 0.029 & 0.932 & 0.03 & 0.256 & 0.798 \\
\hline
\end{tabular}

alncluding mean, standard deviation Time One and Two; mean of the difference $(\bar{x} d)$, standard deviation of the sample of differences (sd), $t$-value and p-value (df = 1 (69).

limited and there is potential for repeating the survey with a larger sample size to estimate the mean difference with more precision.

In summary, the results suggest that the participant group were experiencing elevate perceived stress at Time One and Time Two, MAAS levels similarly remained constant and there was a decrease in PWI scores.

\subsection{Phase Two}

A paired-sample $t$-test and independent $t$-test was completed to address Research Question 2:

2. Does participating in a 6-h Complementary Intervention change, if at all, mindful attention awareness and perceived stress for pre-service teachers? 
TABLE 9 | Summary of the Control Group and Intervention Group Mean Scores for the PSS and MAAS.

\begin{tabular}{|c|c|c|c|c|c|c|c|c|}
\hline & \multicolumn{4}{|c|}{ Control group $(N=79)$} & \multicolumn{4}{|c|}{ Intervention group $(N=20)$} \\
\hline & \multicolumn{2}{|c|}{ Time one } & \multicolumn{2}{|c|}{ Time two } & \multicolumn{2}{|c|}{ Time one } & \multicolumn{2}{|c|}{ Time two } \\
\hline & Mean & SD & Mean & SD & Mean & SD & Mean & SD \\
\hline 10 & 21.19 & 6.17 & 19.96 & 5.86 & 18.6 & 7 & 14.42 & 4.9 \\
\hline MAAS & 3.49 & 0.72 & 3.48 & 0.81 & 3.49 & 0.6 & 3.9 & 0.85 \\
\hline
\end{tabular}

\subsubsection{Paired-Samples $t$-Test: Intervention Group}

The Shapiro-Wilk test confirmed normal distribution of the pre- and post-program data for the PSS (W $(20)=0.975, p=0.85)$ and MAAS (W $(20)=0.951, p=0.377)$. The pre-program PSS scores indicated that $25 \%$ of the participants reported a score of 24 of higher preintervention, which reduced to 19 in the post-program. A paired sample $t$-test was completed to determine the difference in mean scores $\left(\bar{x}_{d}=3.05, s_{d}=6.3\right)$ for the PSS pre-program $(\mathrm{M}=18.6, \mathrm{SD}=$ $7.04)$ and post-program $(\mathrm{M}=15.55, \mathrm{SD}=6.95)$ for the conditions; $t$ $(19)=2.2, p=0.04)$. The results support the contention that perceived stress levels decreased pre-to post-intervention ( $p$-value less than 0.05 ). The effect size $d=0.48$, indicates that the post-program scores were approximately half a standard deviation lower than the pre-program scores. The $95 \%$ confidence interval for the mean difference is $[-0.096$, 6], indicating a moderate confidence interval (Evans, 1996). The confidence interval suggests that the post-intervention mean score could be 6 points higher or 0.096 points lower than the preintervention score.

Similarly, the difference in mean scores for the MAAS $\left(\bar{x}_{d}=-0.45\right.$, $\left.s_{d}=0.78\right)$ pre-intervention $(\mathrm{M}=3.49, \mathrm{SD}=0.59)$ and postintervention $(\mathrm{M}=3.94, \mathrm{SD}=0.85)$ with the conditions $t(19)=$ $-2.57, p=0.019)$ suggest an increase in MAAS scores pre- and postintervention. This is supported by the negative effect size $(d=-0.57)$, indicating that the post-program MAAS scores were approximately half a standard deviation higher than the pre-program MAAS scores. The $95 \%$ confidence interval for MAAS score was [-0.82, -0.084$]$, indicating a narrow range which is a result of the small sample size, however, the medium effect size warrants further investigation. Therefore, the results indicated there was a change in perceived stress and attention awareness. However, due to the small sample size, the results could be investigated further with a larger participant sample. As outlined in the Procedure (Figure 1) only the quantitative datasets are reported in this paper. The mixed-methods design was included to improve the quality of the inferences (Teddlie and Tashakkori, 2009) and overcome the limitation of the smaller participant size and limited access to a control group.

\subsubsection{Intervention Group and Control Group}

To overcome the limitation of a control group, the participant sample from Phase One was included. This allowed for the additional exploration of the results from the intervention. A $t$-test for independent data was completed and the participant sample from the phase one (Time One) $(N=79)$ as the control group (Table 9). The participant group from phase one did not participate in the program (intervention). This analysis was included to provide additional information for Research Question 2. The Levene's Test for Equality of Variances $(F=1.9, p=0.17)$ was larger than 0.05 and
TABLE 10 | Independent Sample t-test Results Summaryª .

\begin{tabular}{llcccc}
\hline & & \multicolumn{4}{c}{ Independent samples } \\
\cline { 3 - 6 } & & $\overline{\mathbf{x}}_{\mathbf{d}}$ & $\mathbf{T}$ & $\hat{\mathbf{d}}$ & $\boldsymbol{p}$-value \\
\hline \multirow{2}{*}{ Time One } & MAAS & 0.0074 & 0.04 & 0.01 & 0.14 \\
\multirow{3}{*}{ Time Two } & PSS & 2.589 & 1.6 & 0.41 & 0.11 \\
& MAAS & -0.4482 & -2.1 & -0.50 & 0.03 \\
& PSS & 5.541 & 3.794 & 0.97 & 0.001
\end{tabular}

alncluding the mean of the difference $(\bar{x} d)$, effect size $(\hat{d}), t$-value and p-value.

not significant, therefore equal variance was assumed. The independent samples $t$-test suggested the difference was not statistically significant, $t(92)=1.6, p=0.11$. The effect size $(d=$ 0.41 , calculated with the pooled standard error of 6.29 ) and the $95 \%$ confidence interval was $[-0.59,5.78]$. The results indicate no significant difference between the control and intervention group's perceived stress scores before the intervention.

Likewise, the MAAS scores for the control group $(\mathrm{M}=3.49$; $\mathrm{SD}=0.72 ; n=72$ ) and the pre-program intervention group scores $(\mathrm{M}=3.490 ; \mathrm{SD}=0.6 ; n=20)$ did not produce a statistically significant result $(t(90)=0.04, p=0.14)$, equal variance was assumed $(F=0.88, p=0.35)$. The effect size was not significant $(d=0.01$, calculated with the pooled standard error of 0.67$)$ with a $95 \%$ confidence interval of $[-0.33,0.34]$ (see Table 10).

The same process was completed to explore the post-program findings. The PSS scores from the Phase One, Time Two $(M=19.96$; $\mathrm{SD}=5.86)$ were compared to the participants in the intervention group (post-intervention) $(\mathrm{M}=14.42 ; \mathrm{SD}=4.9 ; n=19)$. Equal variance was assumed $(F=0.801, p=0.37)$. The independent samples $t$-test suggested the difference was statistically significant, $t(96)=$ 3.794, $p<0.001$. The effect size $(d=0.97$, calculated with the pooled standard error of 5.7) was large, indicating the perceived stress scores from the intervention group were approximately one standard deviation lower than the control group.

The same analysis was completed for the MAAS scores for the same sample from Phase One $(n=72$; Time Two $)(\mathrm{M}=3.48, \mathrm{SD}=$ $0.81)$ and the intervention group (post-intervention) $(\mathrm{M}=3.9, \mathrm{SD}=$ $0.85 ; N=20)$. The $p$-value from the F-test $(F=0.39, p=0.53)$ was larger than 0.05 therefore equal variance was assumed. The independent sample $t$-test suggested the difference was statistically significant, $t(91)=-2.1, p=0.03$. The effect size $(d=-0.50$, calculated with the pooled standard error of 0.80 ) suggested a medium effect size (Evans, 1996). This indicates that the intervention group had a higher MAAS score at Time Two than the control group.

\section{DISCUSSION}

The OECD outlined in the Teaching and Learning International Survey (OECD, 2020) that $66 \%$ of teachers have no regrets about their career choice. However, the data indicated that those who questioned their career choice were more likely to be employed in public (Government) schools, younger (under 30), and less experienced (i.e., under 5 years of experience). It could be argued that providing wellbeing support at the pre-service level may influence or assist with the transition into the early career period. In addition, there are 
downstream impacts for the classroom (see Flook et al., 2013; Skinner and Beers, 2016; Hepburn, 2020). Raising awareness of the signs of stress, teaching effective stress-management techniques and promoting healthy work-life balance are essential to reduce burnout at the pre-service level (Greer and Greer, 1992). Preservice teachers often lack the skills and strategies to achieve emotional balance and reduce feelings of helplessness and frustration (Lindqvist et al., 2017) and it is recommended that techniques are provided and taught to lessen the physical and mental strain associated with stress (Travers, 2017).

\subsection{Perceived Stress Levels, Mindful Attention Awareness and Subjective Wellbeing}

Phase One aimed to identify what changes, if any, were there in the levels of perceived stress, subjective wellbeing, coping strategies, and mindful attention awareness for pre-service teachers from the start (Time One) to the end of the academic year (Time Two).

The overall decrease in PSTs subjective wellbeing (PWI scores) from Time One to Time Two $(p=0.04)$ may be influenced by contextual factors. The results indicated there was neither a significant increase nor decrease in perceived stress, regardless of year level (e.g. first-year or final-year). The results support the argument by Stallman and Hurst (2016) that stress levels for PSTs remain constant across the duration of the academic year. The findings illustrated that the participant sample remained above the reported "average" stress level of 13 (Cohen et al., 1983) and the age-matched reported norms. The "high" stress scores of 20 or above at Time One and Time Two, support Stallman's argument that PSTs experience chronic stress levels across the duration of the academic year. Reporting higher levels of perceived stress at the start of the academic year could be influenced by contextual factors such as enrolling in new courses, scheduling of personal commitments, transitioning from full-time work or high school settings to university settings (Goddard and O'Brien, 2006; Gustems-Carnicer and Calderón, 2013). The stress levels of graduate and undergraduate PSTs have previously been explored by Geng et al. (2015); however, to date, there are limited studies that examine the relationships between perceived stress and wellbeing for PST.

At the end of the academic year, the "final-year" sub-group reported lower perceived stress and higher subjective wellbeing, which may have been influenced by contextual factors such as completing final assessment items and practicum placements and securing employment. Drawing on the experiences detailed in the literature, final-year education students leaving the university setting and transitioning from pre-service to in-service teachers may experience feelings of insecurity, self-doubt and confusion (Le Maistre and Paré, 2010; Le Cornu, 2013) which could potentially influence subjective wellbeing. PSTs entering the profession may experience emotional reactions to their changing professional identity, subsequently impacting subjective wellbeing (Pillen, Beijaard and den Brok., 2013).

The mid-degree participants experienced a decrease in perceived stress and maintained subjective wellbeing. Mid-degree students who have completed their first teaching practicum may reflect on their professional ability and their decision to enter the teaching profession (Chaplain, 2008; Murray-Harvey et al., 2000). Whereas first-year participants PSS scores were maintained and the participants reported lower subjective wellbeing. This may reflect the significant changes experienced by PSTs when moving from high school education to tertiary education or returning to study (e.g., leaving paid employment) (Goddard, O'Brien and Goddard, 2006; Le Maistre and Paré, 2010).

The mean scores were included in the results for each subgroup in the participant sample; however, a detailed exploration of the differences between the sub-groups was beyond the scope of present study. The differences between the sub-groups warrant further investigation with a larger participant sample. A recommendation for future research would be to examine the levels of subjective wellbeing, mindful attention awareness and perceived stress for different cohorts of education students (e.g., degree type, entry-level). Additional information surrounding the experiences of PST may provide guidance and inform the development of ITT courses and programs.

The results suggest the participants engaged in planning, which is a proactive coping strategy; however, social support (emotional support) was lower. Acceptance relates to mindful attention awareness (mindfulness) (Skinner and Beers, 2016), and this was the highest reported strategy even though the MAAS scores for the participant sample were below the reported norm average. Although there was no significant change in coping strategies, the highest reported strategies were acceptance, selfblame, planning, and self-distraction. The results indicated there was neither an increase nor a decrease in MAAS scores and coping mechanisms. Proactive and active coping strategies have a positive influence on psychological distress (Gustems-Carnicer and Calderón, 2013), and positive coping strategies, including seeking social support are positively correlated to psychological wellbeing (Deasy et al., 2014).

\subsection{Intervention Group-Mindful Attention Awareness and Perceived Stress}

Due to the unique design of the intervention in the present study (3-week duration, content relating to holistic wellbeing, theoretical and physical components), there are limited studies that allow for a direct comparison of the findings. However, it has been argued that there is a relationship between attention awareness, perceived stress and subjective wellbeing (Hepburn, 2020), and wellbeing-based teacher training education can have a positive impact on classroom practise and PST wellbeing (Soloway, 2016).

As predicted in the introduction, there was a significant decrease in perceived stress and an increase in mindful attention awareness. The intervention group pre-program PSS scores were above the aged-matched reported norm score but similar to the "high stress" control group. Likewise, the preprogram MAAS scores were not significantly different compared to the control group, indicating that the participant's baseline scores aligned with the larger participant sample (control group).

The post-program PSS and MAAS scores produced a statically significant difference. The large effect size for PSS scores indicated that 
the intervention group were approximately one standard deviation lower than the control group. The medium effect size for MAAS indicated that the intervention group reported an increase in MAAS whereas the control group experienced no change. Therefore, the results suggest that the pre-service teachers who completed a 3-week wellbeing program experienced increased attention awareness and decreased perceived stress compared to individuals who did not complete the Integrated Wellbeing and Stress Management program.

Previous research has indicated a general pattern of a positive correlation between attention awareness and wellbeing and negative correlation with perceived stress with participants reporting a decrease in perceived stress and increased mindful attention awareness after a 6-week MBSR intervention (Hue and Lau, 2015). The 6-week mindfulness program for pre-service teachers conducted by Kerr et al. (2017) presented evidence that the program was effective with regards to emotion regulation, decreasing perceived stress and increasing mindfulness. Diaphragmatic breathing practices were included in the intervention and may relate to the increase in attention awareness and decreased perceived stress. There is a wide variety of breathing practises and techniques included in pranayama (see Rosen, 2002). Inefficient breathing can trigger the sympathetic response (via the afferent vagal nerve). This breathing pattern is associated with the fight-flight-freeze response, commonly associated with feelings of anxiety, fear and fatigue. Efficient breathing, on the other hand, stimulates the parasympathetic response via afferent vagal nerves. Diaphragmatic breathing creates a sense of calm and ease in the body (Rosen, 2002). The sequencing in the physical practice in the intervention emphasized synchronization within the breath and movement from one pose to the next. A significant characteristic of a posture (asana) is the emphasis on kinesthesis, interoceptive and proprioceptive awareness. It has been hypothesized that the movement component of yoga-based practises facilitates the processing and integration of interoceptive and proprioceptive signals in the brain (Schmalzl et al., 2016). It could be suggested that the physical practice support the increased sense of awareness experienced by the participants (e.g. increased MAAS scores). Increased awareness of the stress response is a recommendation for reducing burnout (Greer and Greer, 1992; Travers, 2017).

Introducing techniques and strategies for promoting health and wellbeing during initial teacher training at university may provide valuable support for PSTs and enable them with strategies to utilize and implement whilst at university and prior to entering the school environment, consequently laying a foundation for supporting health and wellbeing from the onset. The foundational approach to wellbeing could be built upon and extended during the early career period to provide those entering the profession with valuable ongoing support for their wellbeing (see Hepburn et al., 2021). Like other pilot studies, including wellbeing programs and initiatives, the small sample size was a limitation; however, the results warrant further investigation with a larger participant sample.

\subsection{Limitations and Further Research}

Relying on participants to provide a valid email address for the Time Two survey influenced the sample size, due to invalid responses.
Timing of the survey (e.g. assessment period) may have limited the sample due to time constraints and time required to complete the survey or attend the program. Participation was not linked to coursework (e.g. credit towards assessment) therefore it was not incentivized. Participation required that the PST attended the session outside of class hours (e.g. Saturday or weekday evenings). Therefore, clashing commitment (e.g. part time work) limited the participant sample. The small participant sample size presented a limitation in the study design and therefore the results may not be generalizable. Similarly, the participants were self-selected however, they had limited previous experience with mind-body therapies or CIs and MBIs. Further exploration of the experiences of PST could be incorporated into ITT programs including longitudinal studies examining the transition of teachers from the pre-service to early career period.

\section{CONCLUSION}

The workplace has been referred to as one of the priority settings for health promotion by the World Health Organization (WHO, 2020). The WHO outline that to ensure success in the current globalized marketplace, companies and organizations must ensure their workforce is healthy, motivated and qualified. Consequently, health promoting workplaces and workplace health promotion is becoming increasingly recognized as essential for success. It is unrealistic to expect that supporting wellbeing should not rest solely on the individual teachers. If workplaces are becoming the site for health promotion, should universities similarly provide such support for their students prior to entering the workforce?

\section{DATA AVAILABILITY STATEMENT}

Data available on request due to restrictions. The data are not publicly available due to the conditions specified in the ethics application.

\section{ETHICS STATEMENT}

The study was approved by the Human Research Ethics Committee (HRECs) from The University of Queensland, Australia (approval number: 2017002108). The study was guided by the Code for Responsible Conduct of Research from the National Statement on Ethical Conduct in Human Research (2007) (Australian Research Council and Universities, 2018).

\section{AUTHOR CONTRIBUTIONS}

All authors listed have made a substantial, direct, and intellectual contribution to the work and approved it for publication. Conceptualization, S-JH; methodology, S-JH; software, S-JH; validation, $\mathrm{S}-\mathrm{JH}, \mathrm{AC}$, and $\mathrm{LM}$; formal analysis, $\mathrm{S}-\mathrm{JH}$; investigation, S-JH; writing-original draft preparation, S-JH; 
writing-review and editing, S-JH, AC, and LM; supervision, AC and LM; project administration, S-JH; funding acquisition, S-JH.

\section{FUNDING}

This research was supported by an Australian Government Research Training Program Scholarship.

\section{REFERENCES}

Australian Bureau of Statistics (2021) Household Impacts of COVID-19 Survey. Accessed: Household Impacts of COVID-19 Survey | Australian Bureau of Statistics (abs.gov.au) Access date: May 2021.

Australian Research Council and Universities (2018). National Statement on Ethical Conduct in Human Research 2007. Canberra: National Health and Medical Research Council. Available at: www.nhmrc.gov.au/guidelines/publications/e72.

Baer, R. A., Smith, G. T., Hopkins, J., Krietemeyer, J., and Toney, L. (2006). Using Self-Report Assessment Methods to Explore Facets of Mindfulness. Assessment. 13 (1), 27-45. doi:10.1177/1073191105283504

Birdsall, B., Pritchard, M., Elison-Bowers, P., and Spann, J. (2011). "Does Integrative Restoration (iRest) Meditation Decrease Perceived Stress Levels and Negative Moods in School Counselors?" in Paper presented at the Ideas and Research You Can Use VISTAS 11. Available at: http://counselingoutfitters. com/vistas/vistas11/Article_84.pdf.

Broderick, P. C., Kabat-Zinn, J., and Kabat-Zinn, M. (2013). Learning to Breathe: A Mindfulness Curriculum for Adolescents to Cultivate Emotion Regulation, Attention, and Performance. Oakland, CA: New Harbinger Publications.

Brown, K. W., and Ryan, R. M. (2003). The Benefits of Being Present: Mindfulness and its Role in Psychological Well-Being. J. Pers Soc. Psychol. 84 (4), 822-848. doi:10.1037/0022-3514.84.4.822

Brown, R. P., and Gerbarg, P. L. (2005b). Sudarshan Kriya Yogic Breathing in the Treatment of Stress, Anxiety, and Depression: Part I-Neurophysiologic Model. J. Altern. Complement. Med. 11 (1), 189-201. doi:10.1089/acm.2005.11.189

Brown, R. (2017). The Perceived Impact of Mindfulness Instruction on Pre-Service Elementary Teachers. Child. Education. 93 (2), 136-146. doi:10.1080/ 00094056.2017.1300492

Carlson, L. E., Speca, M., Patel, K. D., and Goodey, E. (2004). Mindfulness-Based Stress Reduction in Relation to Quality of Life, Mood, Symptoms of Stress and Levels of Cortisol, Dehydroepiandrosterone Sulfate (DHEAS) and Melatonin in Breast and Prostate Cancer Outpatients. Psychoneuroendocrinology. 29 (4), 448-474. doi:10.1016/S0306-4530(03)00054-4

Carmody, J., and Baer, R. A. (2008). Relationships Between Mindfulness Practice and Levels of Mindfulness, Medical and Psychological Symptoms and WellBeing in a Mindfulness-Based Stress Reduction Program. J. Behav. Med. 31 (1), 23-33. doi:10.1007/s10865-007-9130-7

Chambers, J., Phillips, B., Burr, M., and Xiao, D. (2016). Effects of Meditation on Stress Levels of Physical Therapist Students. J. Phys. Ther. Education. 30 (3), 33-39. doi:10.1097/00001416-201630030-00007

Cohen, S., Kamarck, T., and Mermelstein, R. (1983). A Global Measure of Perceived Stress. J. Health Soc. Behav. 24 (4), 385-396. doi:10.2307/2136404

Cohen, S. (1994). The Perceived Stress Scale. Menlo Park, CA: Mind Garden Inc, 1-5. Available at: http://www.mindgarden.com/documents/PerceivedStressScale.pdf.

Cope, S. (2006). The Wisdom of Yoga: A Seeker's Guide to Extraordinary Living. New York: Bantam.

Creswell, J. (2014). Educational Research: Planning, Conducting and Evaluating Quantitative and Qualitative Research. 4th ed. Harlow, Essex, UK: Pearson.

Creswell, J., and Plano Clark, V. L. (2018). Designing and Conducting Mixed Methods Research. 3rd ed. Thousand Oaks: Sage.

Deasy, C., Coughlan, B., Pironom, J., Jourdan, D., and Mannix-McNamara, P. (2014). Psychological Distress and Coping Amongst Higher Education Students: A Mixed Method Enquiry. PLoS ONE. 9 (12), el15193-23. doi:10.1371/journal.pone.0115193

Eastman-Mueller, H., Wilson, T., Jung, A. K., Kimura, A., and Tarrant, J. (2013). iRest Yoga-Nidra on the College Campus: Changes in Stress, Depression,

\section{ACKNOWLEDGMENTS}

The authors would like to knowledge the support of the Queensland Department of Education and Training and Brisbane Catholic Education. The willingness of the teachers to volunteer for the program, provide feedback and contribute to this research was greatly appreciated. S-JH would like to acknowledge the support of their supervisory team from The University of Queensland.

Worry, and Mindfulness. Int. J. Yoga Therap. 23 (2), 15-24. doi:10.17761/ ijyt.23.2.r8735770101m8277

Evans, J. (1996). Straight Forward Statistics for the Behavioral Sciences. Pacific Grove, CA: Brooks/Cole Publishing.

Feuerstein, G. (2011). Encyclopedia of Yoga and Tantra. Boulder, CO: Shambhala Publications Inc.

Flook, L., Goldberg, S. B., Pinger, L., Bonus, K., and Davidson, R. J. (2013). Mindfulness for Teachers: A Pilot Study to Assess Effects on Stress, Burnout and Teaching Efficacy. Mind Brain Educ. 7 (3), 182-195. doi:10.1111/ mbe. 12026

Frank, J. L., Reibel, D., Broderick, P., Cantrell, T., and Metz, S. (2015). The Effectiveness of Mindfulness-Based Stress Reduction on Educator Stress and Well-Being: Results from a Pilot Study. Mindfulness. 6 (2), 208-216. doi:10.1007/s12671-013-0246-2

Gard, T., Brach, N., Hölzel, B. K., Noggle, J. J., Conboy, L. A., and Lazar, S. W. (2012). Effects of a Yoga-Based Intervention for Young Adults on Quality of Life and Perceived Stress: The Potential Mediating Roles of Mindfulness and Self-Compassion. The Journal of Positive Psychology, 7(3), 165-175. doi:10.1080/17439760.2012.667144

Gard, T., Noggle, J. J., Park, C. L., Vago, D. R., and Wilson, A. (2014). Potential SelfRegulatory Mechanisms of Yoga for Psychological Health. Front. Hum. Neurosci. 8 (770), 770-820. doi:10.3389/fnhum.2014.00770

Geng, G., Midford, R., and Buckworth, J. (2015). Investigating the Stress Levels of Early Childhood, Primary and Secondary Pre-service Teachers During Teaching Practicum. J. Teach. Education Sustainability. 17 (1), 35-47. doi:10.1515/jtes-2015-0003

Grant-Smith, D, de Zwaan, L, Chapman, R, and Gillett-Swan, J. 'It's the Worst, but Real Experience is Invaluable': Pre-Service Teacher Perspectives of the Costs and Benefits of Professional Experience. In: D Heck and A Ambrosetti, editors. Teacher Education In and For Uncertain Times. Singapore: Springer; 2018. p. 15-33.

Greer, J. G., and Greer, B. B. (1992). Stopping Burnout before it Starts: Prevention Measures at the Preservice Level. Teach. Education Spec. Education. 15 (3), 168-174. doi:10.1177/088840649201500303

Gold, E., Smith, A., Hopper, I., Herne, D., Tansey, G., and Hulland, C. (2010). Mindfulness-Based Stress Reduction (MBSR) for Primary School Teachers. Journal of Child and Family Studies, 19(2), 184-189. doi:10.1007/s10826-0099344-0

Gu, Q., and Day, C. (2007). Teachers Resilience: A Necessary Condition for Effectiveness. Teach. Teach. Education. 23 (8), 1302-1316. doi:10.1016/j.tate.2006.06.006

Gustems-Carnicer, J., and Calderón, C. (2013). Coping Strategies and Psychological Well-Being Among Teacher Education Students. Eur. J. Psychol. Educ. 28 (4), 1127-1140. doi:10.1007/s10212-012-0158-x

Harris, A. R., Jennings, P. A., Katz, D. A., Abenavoli, R. M., and Greenberg, M. T. (2016). Promoting Stress Management and Wellbeing in Educators: Feasibility and Efficacy of a School-Based Yoga and Mindfulness Intervention. Mindfulness. 7 (1), 143-154. doi:10.1007/s12671-015-0451-2

Harris, G. E. (2011). Individual Stress Management Coursework in Canadian Teacher Preparation Programs. Can. J. Education. 34 (4), 104-117.

Hemmings, B., and Hockley, T. (2002). Student Teacher Stress and Coping Mechanisms. Education Rural Aust. 12 (2), 25-35.

Hepburn, S.-J. (2020) Integrated Wellbeing for Teachers: A Mixed-Methods Study Investigating Attention Awareness, Perceived Stress and Subjective Wellbeing and a Complementary Intervention for Pre-Service and Early Career Teachers. Ph.D. Thesis, The University of Queensland, Brisbane, Australia.

Hepburn, S.-J., Carroll, A., and McCuaig-Holcroft, L.(2021) A Complementary Intervention to pPromote Wellbeing and Stress Management for Early Career 
Teachers. Int. J. Environ. Res. Public Health, 18, 6320. doi:10.3390/ ijerph 18126320

Hester, N. (2017). in Yoga and Teacher Stress: An Examination of a WorkplaceBased Yoga Practice on the Perceived Stress of Elementary School Teachers. Editor D. dissertation (Wisconsin, United States: Edgewood College). Available at: https://search.proquest.com/docview/1969169426.

Hopkins, W. S., Hoffman, S. Q., and Moss, V. D. (1997). Professional Development Schools and Preservice Teacher Stress. Action. Teach. Education. 18 (4), 36-46. doi:10.1080/01626620.1997.10463362

Hue, M.-T., and Lau, N.-S. (2015). Promoting Well-Being and Preventing Burnout in Teacher Education: A Pilot Study of a Mindfulness-Based Programme for Pre-service Teachers in Hong Kong. Teach. Development. 19 (3), 381-401. doi:10.1080/13664530.2015.1049748

Hwang, Y.-S., Goldstein, H., Medvedev, O. N., Singh, N. N., Noh, J.-E., and Hand, K. (2019). Mindfulness-Based Intervention for Educators: Effects of a SchoolBased Cluster Randomized Controlled Study. Mindfulness. 10, 1417-1436. doi:10.1007/s12671-019-01147-1

Ivtzan, I. (2016). "Mindfulness in Positive Psychology-An Introduction," in Mindfulness in Positive Psychology. Editors I. Ivtzan and T. Lomas (Oxford, UK: Routledge), 1-12.

Jelinek, C. A. (1986). Stress and the Pre-Service Teacher. The Teacher Educator, 22(1), 2-8. doi:10.1080/08878738609554886

Jennings, P. A., Frank, J. L., Snowberg, K. E., Coccia, M. A., and Greenberg, M. T. (2013). Improving Classroom Learning Environments by Cultivating Awareness and Resilience in Education (CARE): Results of a Randomized Controlled Trial. Sch. Psychol. Q. 28 (4), 374-390. doi:10.1037/ spq0000035

Jennings, P. A., Brown, J. L., Frank, J. L., Doyle, S., Oh, Y., Davis, R., et al. (2017). Impacts of the CARE for Teachers Program on Teachers' Social and Emotional Competence and Classroom Interactions. J. Educ. Psychol. 109 (7), 1010-1028. doi:10.1037/edu0000187

Kabat-Zinn, J. (1991). Full Catastrophe Living: Using the Wisdom of Your Body and Mind to Face Stress, Pain, and Illness. New York, NY: Dell Publishing Co..

Katz, D. A., Greenberg, M. T., Jennings, P. A., and Klein, L. C. (2016). Associations Between the Awakening Responses of Salivary a-Amylase and Cortisol With Self-Report Indicators of Health and Wellbeing Among Educators. Teach. Teach. Education. 54, 98-106. doi:10.1016/j.tate.2015.11.012

Kemeny, M. E., Foltz, C., Cavanagh, J. F., Cullen, M., Giese-Davis, J., Jennings, P., et al. (2012). Contemplative/emotion Training Reduces Negative Emotional Behavior and Promotes Prosocial Responses. Emotion. 12 (2), 338-350. doi:10.1037/a0026118

Kerr, S. L., Lucas, L. J., DiDomenico, G. E., Mishra, V., Stanton, B. J., Shivde, G., et al. (2017). Is Mindfulness Training Useful for Pre-Service Teachers? an Exploratory Investigation. Teach. Education. 28 (4), 349-359. doi:10.1080/ 10476210.2017.1296831

Kim, S. H., Schneider, S. M., Kravitz, L., Mermier, C., and Burge, M. R. (2013). Mind-Body Practices for Post-Traumatic Stress Disorder. Journal of Investigative Medicine, 61(5), 827-834. doi:10.231/ JIM.0b013e3182906862

Kostanski, M. (2007). "The Role of Mindfulness in Reducing Stress for Pre-service Students," in Paper presented at the Australian Association for Research in Education Conference, Fremantle. Available at: http://www.aare.edu.au/data/ publications/2007/kos07569.pdf.

Le Cornu, R. (2013). Building Early Career Teacher Resilience: The Role of Relationships. Ajte. 38 (4), 1-16. doi:10.14221/ajte.2013v38n4.4

Le Maistre, C., and Paré, A. (2010). Whatever it Takes: How Beginning Teachers Learn to Survive. Teach. Teach. Education. 26 (3), 559-564. doi:10.1016/j.tate.2009.06.016

Lee, R. M. (1993). Doing Research on Sensitive Topics. London, UK: Sage Publications.

Lindqvist, H., Weurlander, M., Wernerson, A., and Thornberg, R. (2017). Resolving Feelings of Professional Inadequacy: Student Teachers' Coping With Distressful Situations. Teach. Teach. Education. 64, 270-279. doi:10.1016/j.tate.2017.02.019

Mansfield, C. F., Beltman, S., Broadley, T., and Weatherby-Fell, N. (2016). Building Resilience in Teacher Education: An Evidenced Informed Framework. Teach. Teach. Education. 54, 77-87. doi:10.1016/j.tate.2015.11.016

McCall, T. B. (2007). Yoga as Medicine: The Yogic Prescription for Health and Healing. New York, NY: Bantam Books.
Miyahara, M., Harada, T., Tanaka, S., Fukuhara, H., Kano, T., Ono, T., et al. (2017). Mindfulness Meditation for Future Early Childhood Teachers in Japan. Teach. Teach. Education. 65, 136-144. doi:10.1016/j.tate.2017.03.007

Morris, J. E., and Morris, G. W. (1980). Stress in Student Teaching. Action. Teach. Education. 2 (4), 57-62. doi:10.1080/01626620.1980.10519033

Murray-Harvey, R., T. Slee, P., Lawson, M. J., Silins, H., Banfield, G., and Russell, A. (2000). Under Stress: The Concerns and Coping Strategies of Teacher Education Students. Eur. J. Teach. Education. 23 (1), 19-35. doi:10.1080/713667267

OECD (2020). Teaching and Learning International Survey 2018 Insights and Interpretations. Available at: www.oecd.org/education/talis.

Philippot, P., Chapelle, G., and Blairy, S. (2002). Respiratory Feedback in the Generation of Emotion. Cogn. Emot. 16 (5), 605-627. doi:10.1080/02699930143000392

Poulin, P. A., Mackenzie, C. S., Soloway, G., and Karayolas, E. (2008). Mindfulness Training as an Evidenced-Based Approach to Reducing Stress and Promoting Well-Being Among Human Services Professionals. Int. J. Health Promot. Education. 46 (2), 72-80. doi:10.1080/14635240.2008.10708132

Pradhan, B. (2014). Yoga and Mindfulness Based Cognitive Therapy: A Clinical Guide. New York, NY: Springer International Publishing.

QCT. (2021). Queensland Teachers Annual Report 2019. Retrieved from: https:// www.qct.edu.au/about/corporate-publications Date accessed: March 2021.

Qualtrics(2005). Qualtrics. Provo, Utah, USA. Available at: www.qualtrics.com.

Roeser, R. W., Schonert-Reichl, K. A., Jha, A., Cullen, M., Wallace, L., Wilensky, R., et al. (2013). Mindfulness Training and Reductions in Teacher Stress and Burnout: Results from Two Randomized, Waitlist-Control Field Trials. J. Educ. Psychol. 105 (3), 787-804. doi:10.1037/a0032093

Rosen, R. (2002). The Yoga of Breath: A Step-by-step Guide to Pranayama. Boulder, CO: Shambhala Publications Inc.

Ryff, C. D., and Singer, B. (1996). Psychological Well-Being: Meaning, Measurement, and Implications for Psychotherapy Research. Psychother Psychosom. 65 (1), 14-23. doi:10.1159/000289026

Ryff, C. D., and Singer, B. H. (2006). Best News yet on the Six-Factor Model of Well-Being. Soc. Sci. Res. 35 (4), 1103-1119. doi:10.1016/j.ssresearch.2006.01.002

Schmalzl, L., Streeter, C., and Khalsa, S. (2016). "Research on the Psychophysiology of Yoga," in The Principles and Practice of Yoga in Health Care. Editors S. B. Khalsa, L. Cohen, T. McCall, and S. Telles (London, UK: Handspring Publishing Limited), 49-68.

Shapiro, D., and Cline, K. (2004). Mood Changes Associated With Iyengar Yoga Practices: A Pilot Study. Int. J. Yoga Ther. 14 (1), 35-44. doi:10.17761/ ijyt.14.1.47r6323xv20h786u

Sharp, J. E., and Jennings, P. A. (2016). Strengthening Teacher Presence Through Mindfulness: What Educators Say about the Cultivating Awareness and Resilience in Education (CARE) Program. Mindfulness. 7 (1), 209-218. doi:10.1007/s12671-015-0474-8

Skinner, E., and Beers, J. (2016). "Mindfulness and Teachers' Coping in the Classroom: A Developmental Model of Teacher Stress, Coping, and Everyday Resilience," in Mindfulness in Behavioral Health: Handbook of Mindfulness in Education: Integrating Theory and Research into Practice. Editors K. A. Schonert-Reichl and R. W. Roeser (New York, NY: SpringerVerlag), 99-118. doi:10.1007/978-1-4939-3506-2_7

Soloway, G. B. (2016). "Preparing Teacher Candidates for the Present: Investigating the Value of Mindfulness-Training in Teacher Education," in Mindfulness in Behavioral Health: Handbook of Mindfulness in Education: Integrating Theory and Research into Practice. Editors K. A. Schonert-Reichl and R. W. Roeser (New York, NY: Springer-Verlag), 191-205. doi:10.1007/978-1-4939-3506-2_12

Speller, V., Byrne, J., Dewhirst, S., Almond, P., Mohebati, L., Norman, M., et al. (2010). Developing Trainee School Teachers' Expertise as Health Promoters. Health Education. 110 (6), 490-507. doi:10.1108/09654281011087288

Stallman, H. M., and Hurst, C. P. (2016). The University Stress Scale: Measuring Domains and Extent of Stress in university Students. Aust. Psychol. 51 (2), 128-134. doi:10.1111/ap.12127

Stallman, H. M. (2010). Psychological Distress in University Students: A Comparison with General Population Data. Aust. Psychol. 45 (4), 249-257. doi:10.1080/00050067.2010.482109

Streeter, C. C., Gerbarg, P. L., Saper, R. B., Ciraulo, D. A., and Brown, R. P. (2012). Effects of Yoga on the Autonomic Nervous System, Gamma-AminobutyricAcid, and Allostasis in Epilepsy, Depression, and Post-Traumatic Stress Disorder. Med. Hypotheses. 78 (5), 571-579. doi:10.1016/j.mehy.2012.01.021 
Taylor, A. G., Goehler, L. E., Galper, D. I., Innes, K. E., and Bourguignon, C. (2010). Top-Down and Bottom-Up Mechanisms in Mind-Body Medicine: Development of an Integrative Framework for Psychophysiological Research. Explore: The Journal of Science and Healing, 6(1), 29-41. doi:10.1016/j.explore.2009.10.004

Teddlie, C., and Tashakkori, A. (2009). Foundations of Mixed Methods Research: Integrating Quantitative and Qualitative Approaches in the Social and Behavioral Sciences. Thousand Oaks, CA: Sage Publications.

Travers, C. (2017). "Current Knowledge on the Nature, Prevalence, Sources and Potential Impact of Teacher Stress," in Educator Stress: An Occupational Health Perspective. Editors T. M. McIntyre, S. E. McIntyre, and D. J. Francis (Cham, Switzerland: Springer International Publishing), 347-368. doi:10.1007/978-3319-53053-6_2

Turner, S., Zanker, N., and Braine, M. (2012). An Investigation into Teacher Wellbeing During the Teacher Training Year. Des. Technology Education. 17 (2), 21-34.

Wong, J. G. W. S., Cheung, E. P. T., Chan, K. K. C., Ma, K. K. M., and Wa Tang, S. (2006). Web-Based Survey of Depression, Anxiety and Stress in First-Year Tertiary Education Students in Hong Kong. Australian and New Zealand Journal of Psychiatry, 40(9), 777-782. doi:10.1080/j.1440-1614.2006.01883.x
World Health Organization (2020). Occupational Health Workplace Health Promotion. Available at: https://www.who.int/occupational_health/topics/ workplace/en/.

Conflict of Interest: The authors declare that the research was conducted in the absence of any commercial or financial relationships that could be construed as a potential conflict of interest.

Publisher's Note: All claims expressed in this article are solely those of the authors and do not necessarily represent those of their affiliated organizations, or those of the publisher, the editors and the reviewers. Any product that may be evaluated in this article, or claim that may be made by its manufacturer, is not guaranteed or endorsed by the publisher.

Copyright $\odot 2021$ Hepburn, Carroll and McCuaig. This is an open-access article distributed under the terms of the Creative Commons Attribution License (CC BY). The use, distribution or reproduction in other forums is permitted, provided the original author(s) and the copyright owner(s) are credited and that the original publication in this journal is cited, in accordance with accepted academic practice. No use, distribution or reproduction is permitted which does not comply with these terms. 